\title{
Dampak Seruak Dingin Monsun Dingin Asia Terhadap Variabilitas Hujan Di Jawa
}

\author{
Taryono $^{1}$, Fatkhuroyan ${ }^{2}$ \\ ${ }^{1}$ Pusat Informasi Perubahan Iklim BMKG, Jl. Angkasa 1No.2 Kemayoran Jakarta 10720 \\ ${ }^{2}$ Pusat Penelitian dan Pengembangan BMKG, Jl. Angkasa 1No.2 Kemayoran Jakarta 10720 \\ Email : samtara@yahoo.com
}

\begin{abstract}
Cold surge is a cold air mass flows from Central Asia near Tibetan Plateau through south china sea into western part of Indonesia. The aim of the paper is to investigate the cold surge impacts to rainfall in Java. It clasify the cold surge based on to the strength by calculating data of wind surface from ECMWF ERA-Interim for 30 years. Then a composite rainfall and wind analysis was carried out on the impact of cold surge. The analysis shows that weak cold surge had impact on the decrease of about 15\% of rainfall in Java which associated with Borneo Vortex. While the strong cold surge had an impact on the increase of about $43 \%$ of rainfall in Java..
\end{abstract}

Keywords: Cold surge, Java, Rainfall.

\begin{abstract}
Abstrak: Seruak Dingin (Cold surge) merupakan aliran masa udara dingin yang berasal dari daratan Asia sekitar Tibet melalui Laut Cina Selatan hingga ke wilayah Indonesia bagian barat saat monso on Asia musim dingin. Tujuan penelitian ialah untuk mengkaji dampak seruak dingin terhadap curah hujan di wilayah Jawa. Metode yang dipakai ialah dengan mengklasifikasikan seruak dingin berdasarkan kekuatannya dengan memperhitungkan data angin permukaan ECMWF ERA_Interim selama 30 tahun sejak 1980-2010. Lalu dilakukan analisi komposit curah hujan dan angin terhadap dampak seruak dingin. Hasil analisa menunjukan saat seruak dingin lemah terjadi penurunan curah hujan sebesar 15\% yang berhubungan dengan borneo vortex. Sedangkan saat seruak dingin kuat, berdampak pada kenaikan sekitar $43 \%$ curah hujan di Jawa.
\end{abstract}

Kata kunci: Seruak dingin, Jawa, Cutah Hujan.

\section{PENDAhULUAN}

Monsun merupakan sirkulasi atmosfer yang cukup penting dalam system iklim global. Monsun dingin Asia berhubungan dengan awal musim hujan di Indonesia sekitar bulan Desember hingga Januari (Fauzi et al, 2018). Lim (Lim et al, 2017) mendefinisikan seruak dingin sebagai aliran masa udara dingin yang berasal dari daerah tekanan tinggi di Dataran Tibet. Meskipun aktifitas proses ini sangat singkat, namun berdampak sangat besar terhadap wilayah di Asia Timur hingga Asia Tenggara (Heo et al, 2018). Periode seruak dingin berkisar 5 hinga 14 hari, dan propagasinya dapat mencapai wilayah Indonesia Timur (Xavier et al, 2020).

Ada hubungan yang sangat kuat antara aktifitas seruak dingin dengan meningkatnya aktifitas konveksi di selatan Indonesia (Compo et al, 1999). Penelitian Falahah (Falahah, 1992) menunjukan penetrasi aktivitas seruak dingin mengakibatkan meningkatnya curah hujan di Sebagian besar wilayah Indonesia dari Sumatera hingga timur. Chang (Chang et al, 2005) menyimpulkan bahwa aktifitas seruak dingin mengakibatkan meningkatnya curah hujan lebat di Asia Timur hingga Asia Tenggara. Kajian Wu (Wu et al, 2007) menunjukan bahwa banjir Jakarta 2007 di sebabkan oleh aktifitas seruak dingin. 
Tujuan penelitian ini ialah untuk menginvestigasi efek seruak dingin terhadap distribusi hujan di Jawa.

\section{DATA DAN METODOLOGI}

Aktifitas seruak dingin terjadi saat musim hujan di wilayah Jawa. Periode waktu yang dipakai dalam kajian ini ialah sejak desember 1980 hingga februari 2010. Sedangkan data Curah hujan yang dipakai ialah berasal dari beberapa sumber, antara lain:

\subsection{Curah Hujan Rain Gauges}

Data diperoleh dari Badan Meteorologi Klimatologi dan Geofisika (BMKG). Yaitu dari 10 stasiun meteorology di Jawa, antara lain: Serang, Bandung Geofisik, Tegal, Cilacap, Semarang, Yogyakarta, Surabaya, Malang dan Banyuwangi (Gambar 1). Panjang data dalam kajian ini ialah Desember, Januari dan Februari selama periode desember 2000 hingga februari 2010.

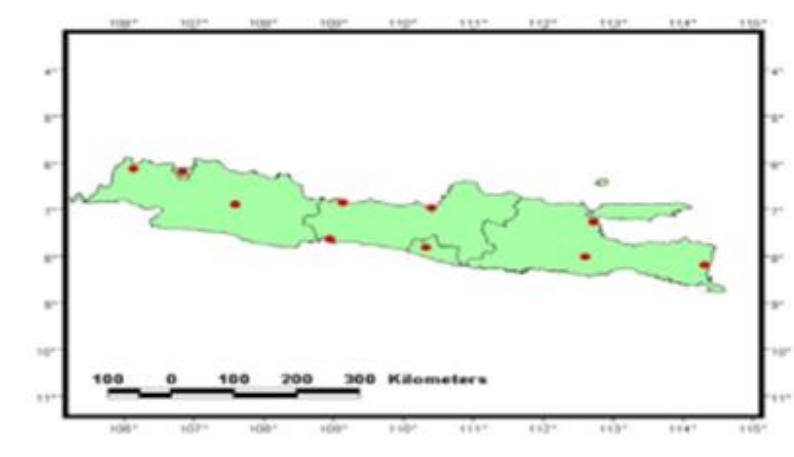

Gambar 1. Lokasi Rain gauge

\subsection{Estimasi Curah Hujan Harian Aphrodite}

Untuk menggambarkan efek aktifitas seruak dingin terhadap distribusi curah hujan secara spasial di wilayah Jawa, maka dipakailah Aphrodite untuk area monsoon asia $\left(60^{\circ} \mathrm{E}-150^{\circ} \mathrm{E}\right.$, $15^{0} \mathrm{~S}-55^{0} \mathrm{~N}$ ) dengan resolusi spasial $0.25^{0} \times 0.25^{0}$ (www.chikyu.ac.jp/precip/) (Yatagai et al, 2012).

\subsection{Angin dan kelembaban spesifik ERA-Interim}

Data angin (komponen U dan V), dan data kelembaban spesifik (q) untuk lapisan standar $(850,700,500,300$ and $200 \mathrm{mb})$ denghan resolusi $1.5^{\circ} \times 1.5^{0}$ diperoleh dari ERA-Interim. Data angin reanalisis di pakai untuk mengidentifikasi kejadian seruak dingin, dengan menggambarkan kondisi angin saat terjadi seruak dingin. Kelembaban spesifik di pakai untuk menentukan transport uap air selama seruak dingin. Data diperoleh dari http://dataportal.ecmwf.int/ (Jones et al, 2017).

\subsection{Indeks Seruak Dingin}

Riehl (Riehl, 1968) mendefinisikan bahwa seruak dingin terjadi Ketika perbedaan tekanan udara antara Hongkong dengan lokasi $115^{\circ} \mathrm{E} / 30^{\circ} \mathrm{N}$ adalah sama atau lebih besar $10 \mathrm{mb}$. Lau (Lau, 1982) menentukan bahwa seruak dingin terjadi jika ada peningkatan komponen angin utara sebesar $7.7 \mathrm{~m} / \mathrm{s}$. Area kejadian seruak dingin dalam kajian ini, berdasarkan penelitian Suppiah dan Wu (Suppiah et al, 1998), seperti dalam Gambar 2. 


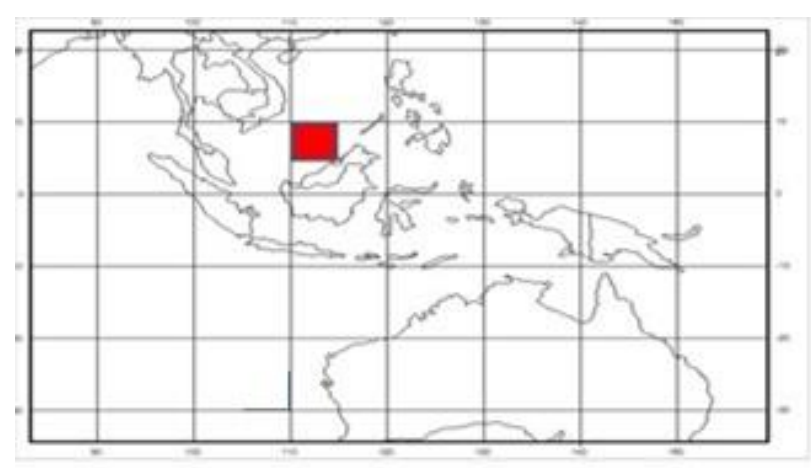

Gambar 2. Area indeks seruak dingin (50-100 N, 1100-1150 E), (Source: Suppiah and Wu, 1998).

\subsection{Analisis Transport Kelembaban}

Dilakukan untuk menentukan kehadiran uap air selama aktifitas seruak dingin. Perhitungan transport uap air berdasarkan persamaan Webster dan Fasullo (Webster et al, 2003)

Transport uap air $=\int_{850}^{300} q \vec{V} d p$

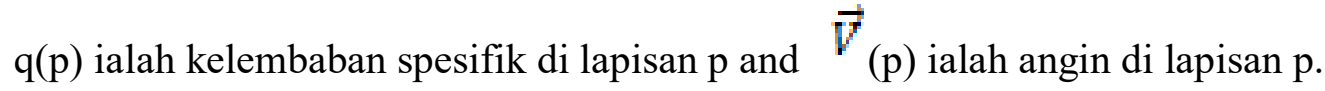

\section{METODE}

Langkah pertama dalam penelitian ialah melakukan identifikasi indeks seruak dingin selama periode 30 tahun dengan menghitung nilai indeks setiap kejadian berdasarkan kriteria angin. Penelitian Falahah (Falahah, 1992) menunjukan bahwa indeks seruak dingin berdasarkan kriteria angin dapat menggambarkan secara langsung aliran massa udara dari laut china selatan ke wilayah Indonesia. Lalu nilai indeks tersebut di pakai saat hari -hari terjadinya aktifitas seruak dingin. Wilayah kejadian ditentukan berdasarkan kajian (Suppiah et al, 1998).

\section{HASIL DAN PEMBAHASAN}

\subsection{Kalkulasi Indeks Seruak Dingin}

Kejadian seruak dingin tercatat sebanyak 142 kali selama 30 tahun sejak 1980 hingga 2010. Indeks tersebut memiliki nilai bervariasi, dengan intensitas terkuat sebesar $12.2 \mathrm{~m} / \mathrm{s}$ dan terlemah sebesar $7.7 \mathrm{~m} / \mathrm{s}$ (Gambar 3).

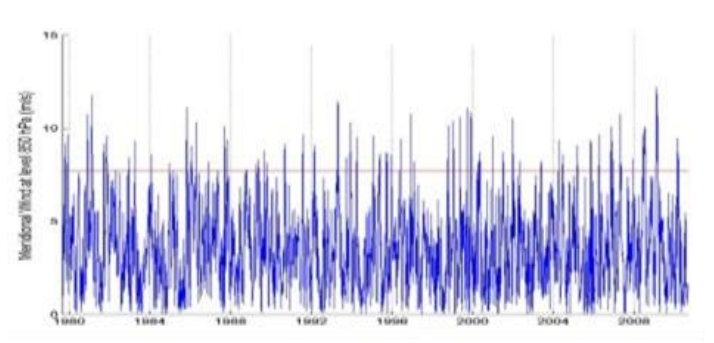

Gambar 3. Nilai Indeks Seruak Dingin selama periode 1980-2010 (garis warna merah menunjukan batas bawah $7.7 \mathrm{~m} / \mathrm{s}$ ). 


\subsection{Identifikasi Jumlah Kejadian Seruak Dingin}

Tabel 1 menunjukan bahwa ada 142 kejadian seruak dingin selama periode 1980-2010. Seruak dingin kuat sebanyak $27 \mathrm{kali}(>10 \mathrm{~m} / \mathrm{s}), 35$ kejadian sedang $(8.9-10 \mathrm{~m} / \mathrm{s})$ dan 80 kejadian lemah $(7.7-8.8 \mathrm{~m} / \mathrm{s})$ yang merupakan kejadian terbanyak.

Tabel 1. Kejadian Seruak Dingin

\begin{tabular}{cccc}
\hline Intensitas(m/s) & Kuat (>10) & Sedang (8.9-10) & $\begin{array}{c}\text { Lemah } \\
\mathbf{( 7 . 7 - 8 . 8 )}\end{array}$ \\
\hline Jumlah Hari & 27 & 35 & 80 \\
\hline
\end{tabular}

\subsection{Pola Sirkulasi Angin}

Gambar 4 menunjukan saat kejadian seruak dingin kuat, maka ada aliran masa udara dari belahan bumi utara yang memasuki wilayah Indonesia. Jika tidak ada gangguan sinoptik disekitar Laut Cina Selatan, seperti vortex di sekitar Kalimantan, maka aliran masa udara tersebut dapat dengan bebas mengalir ke selatan hingga $10^{\circ} \mathrm{S}$. Laut cina selatan merupakan wilayah angin monsoon Asia terkuat (Jeong et al, 2014).

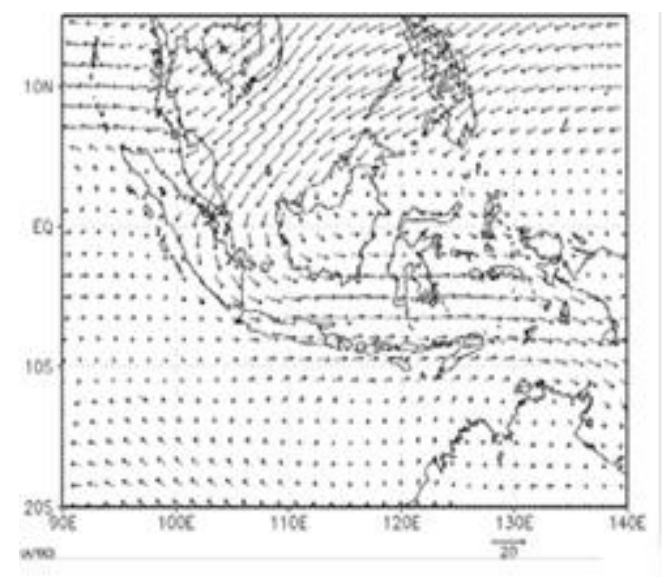

Gambar 4. Pola Angin saat terjadi Seruak Dingin kuat selama periode 1980-2010

Gambar 5 menunjukan bahwa saat kejadian seruak dingin lemah, maka aliran masa udara kuat berasal dari Samudra Hindia sebelah barat Australia berhembus hingga belahan bumi utara sekitar equator. Nampak jelas disekitar area $110^{\circ} \mathrm{E}$, bahwa aliran masa udara tersebut hingga mencapai Jawa. Bahkan aliran masa udara dari belahan bumi selatan tersebut hingga $10^{0} \mathrm{~N}$.

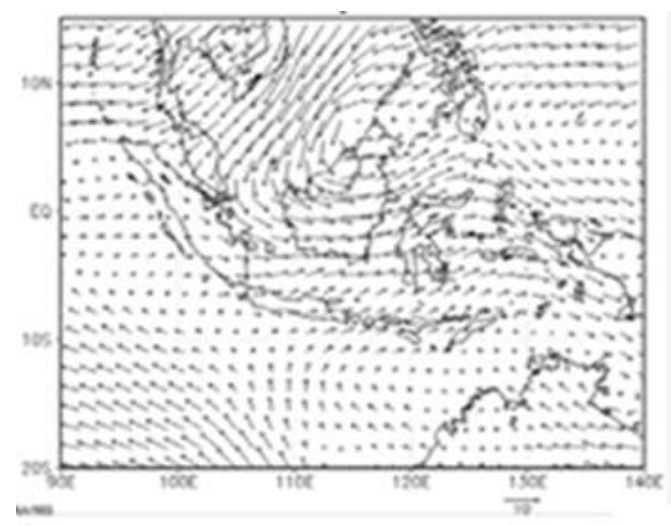

Gambar 5. Pola Angin saat terjadi Seruak Dingin Lemah selama periode 1980-2010. 
Gambar 6 menunjukan pola sirkulasi angin saat seruak dingin sedang (moderate). Pertemuan angin terjadi di sekitar Jawa dan Laut Arafuru, di wilayah $5^{0} \mathrm{~S}$ hingga $10^{0} \mathrm{~S}$, membentang dari Samudera Pasifik hingga Laut Arafuru.

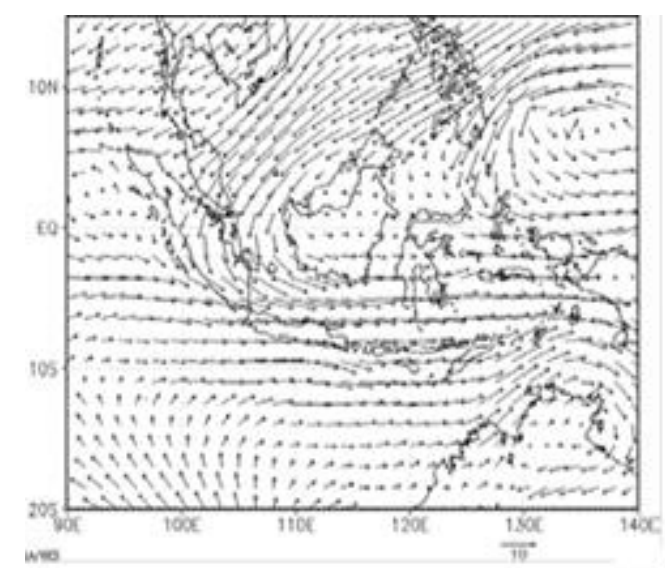

Gambar 6. Pola Angin saat terjadi Seruak Dingin moderat selama periode 1980-2010.

\subsection{Transpor Uap Air}

Gambar 7 menunjukan bahwa selama seruak dingin kuat, uap air Pasifik Barat mengalir ke Laut Cina Selatan melintasi equator hingga memasuki Jawa, sehingga menyebabkan peningkatan uap air di Jawa.Hal ini bertambah kuat dengan tidak adanya interferensi wi Laut Cina Selatan.

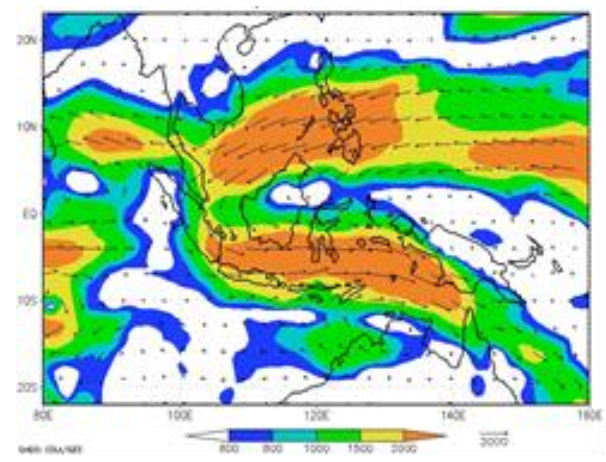

Gambar 7. Distribusi transport uap air $(\mathrm{kg} / \mathrm{sec})$ saat seruak dingin kuat selama periode 19802010 .

Gambar 8 menunjukan bahwa selama seruak dingin lemah, uap air yang memasuki Jawa melemah. Area of $120^{\circ}-130^{\circ} \mathrm{E}$ and sekitar $15^{\circ} \mathrm{N}$ merupakan area dengan uap air paling rendah saat transport uap air dari Pasifik Barat ke Laut Cina Selatan. Area ini bertambah besar sehari setelah seruak dingin. Hal ini menyebabkan transport uap air cross equator dari belahan bumi utara ke belahan bumi selatan yang memasuki Jawa juga berkurang (Hermawanto, 2011). Uap air yang berasal dari Pasifik Barat Sebagian mengalir ke wilayah lintang tinggi sebelum melintasi Laut Cina Selatan. Saat melintasi equator, Sebagian uap air terbagi mengalir ke Samudera Hindia Utara equator. Hal ini berakibat kurangnya suplai uap air ke Jawa sehingga men yebabkan menurunnya cruah hujan di wilayah Jawa. 


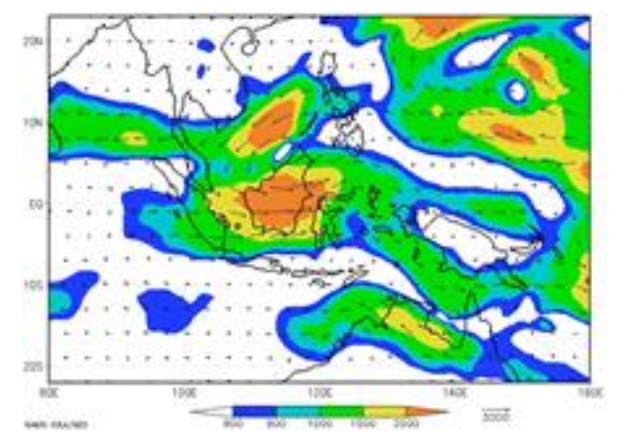

Gambar 8. Distribusi transport uap air $(\mathrm{kg} / \mathrm{sec})$ saat seruak dingin lemah selama periode 1980-2010.

Gambar 9 menunjukann transport uap air saat seruak dingin moderat, Ketika jumlah uap air yang memasuki Jawa berkurang. Hal ini menyebabkan area transport uap air lintas equator di sekitar $100^{\circ}-110^{\circ} \mathrm{E}$ berkurang. Karena setelah melintasi laut Cina selatan, uap air dari Pasifik Barat terbagi mengalir ke Samudera India Utara Equator. Namun Jawa masih mengalami hujan di sebabkan masih ada nya transport uap air ke wilayah ini.

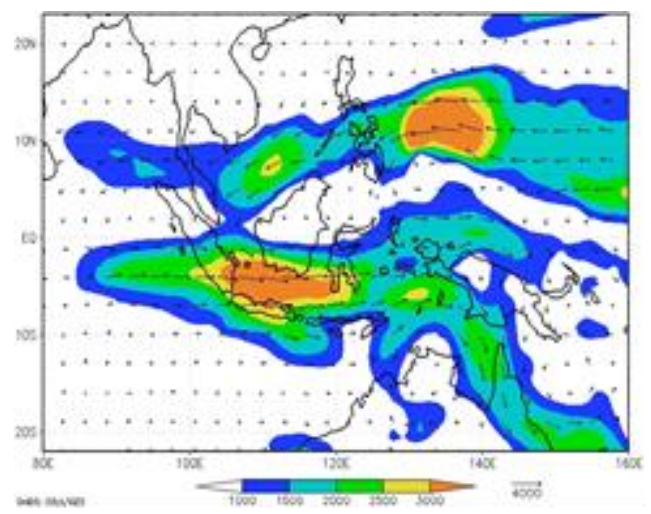

Gambar 9. Distribusi transport uap air $(\mathrm{kg} / \mathrm{sec})$ saat seruak dingin moderat selama periode 1980-2010.

\subsection{Dampak Aktifitas Seruak Dingin terhadap Distribusi Hujan}

Gambar 10 menunjukan Sebagian besar wilayah Jawa, terutama sebelah utara Jawa mengalami peningkatan curah hujan. Bahkan hinga sehari setelah kejadia seruak dingin, hujan menyebar keseluruh Jawa.

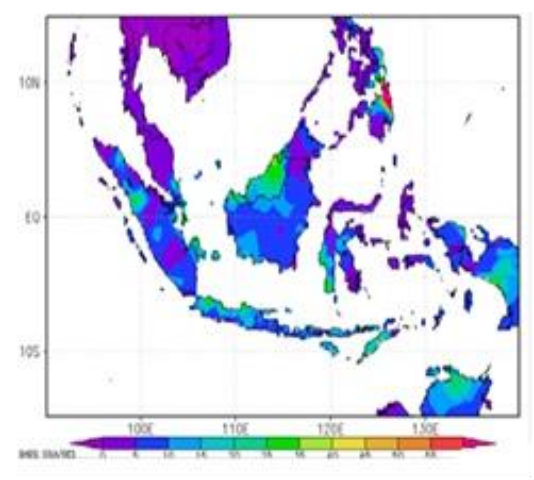

Gambar 10. Distribusi curah hujan (mm/hr) saat seruak dingin kuat selama periode 19802010 . 
Meningkatnya curah hujan di Sebagian besar Jawa saat seruak dingin kuat di akibatkan adanya aliran massa udara kuat yang mengalir dari belahan bumi utara di Laut cina selatan melintasi equatoe hingga ke Jawa. Selain itu, persediaan uap air dari Pasifik Barat dapat mengalir ke Jawa dengan bebas tanpa hambatan.

Sebaliknya, Gambar 11 menunjukan Ketika seruak dingin lemah, maka distribusi curah hujan di Jawa menjadi berkurang bahkan menyebahkan tidak ada nya hujan sehari setelah kejadian seruak dingin.

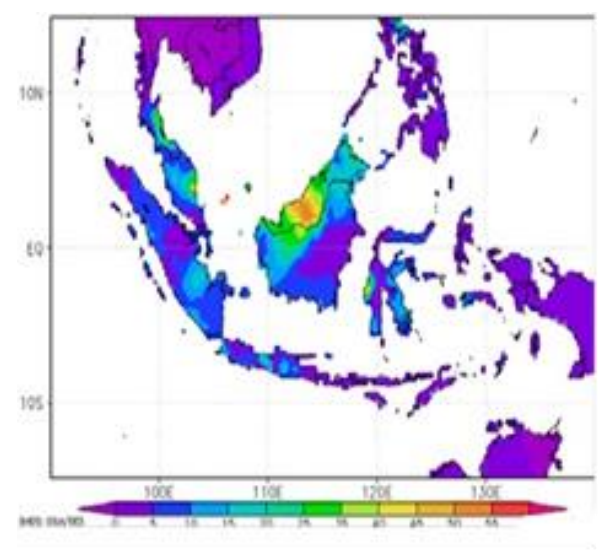

Gambar 11. Distribusi curah hujan ( $\mathrm{mm} / \mathrm{hr}$ ) saat seruak dingin lemah selama periode 19802010.

Gambar 12 menunjukan saat seruak dingin moderat, maka terjadi pertemuan angin di Jawa hingga Nusa Tenggara. Hal ini mengakibatkan masih adanya hujan di Jawa menyebar tidak merata walau tidak sebanyak saat seruak dingin kuat.

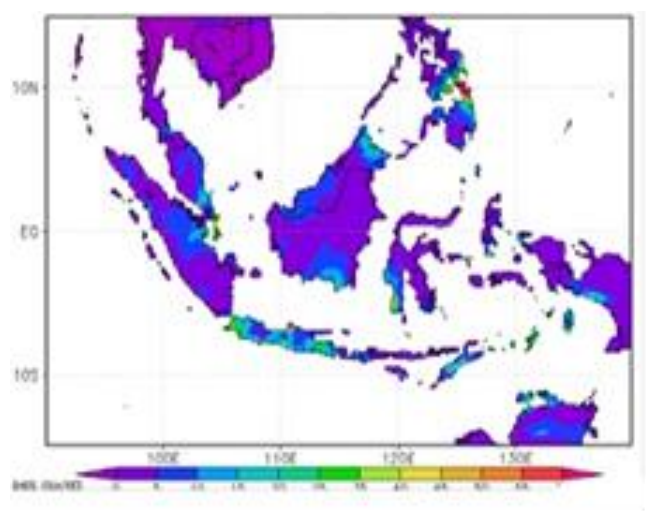

Gambar 12. Distribusi curah hujan ( $\mathrm{mm} / \mathrm{hr})$ saat seruak dingin moderat selama periode 19802010

Hasil analisis jumlah curah hujan saat kejadian seruak dingin dibandingkan dengan rata-rata 10 tahun dari 10 stasiun meterologi di Jawa dalam Tabel 2 menunjukan bahwa saat seruak dingin kuat, maka curah hujan harian meningkat sekitar 43\% terhadap rata-rata curah hujan. Sebaliknya, saat seruak dingin lemah, maka terjadi penurunan curah hujan sebesar $15 \%$. Sementara itu, saat seruak dingin moderat, juga terjadi penurunan curah hujan sebesar $6 \%$. 
Tabel 2. Presentasi Curah Hujan

\begin{tabular}{llll}
\hline Intensitas & Kuat & Sedang & Lemah \\
\hline Peningkatan/penurunan & $+43 \%$ & $-6 \%$ & $-15 \%$ \\
\hline
\end{tabular}

Penelitian Koseki (Koseki et al, 2014) menunjukan bahwa selama seruak dingin kuat, komponen angin utara mengalir bebas ke Jawa dan bersinergi dengan proses angin laut dan angin darat yang menyebakan hujan lebab di pagi hari.

\section{KESIMPULAN}

Aktifitas seruak dingin menyebakan perbedaan distribusi curah hujan di Jawa. Saat seruak dingin kuat, Jawa mengalami peningkatan curah hujan. Hal ini disebabkan karena menguatnya aliran massa udara dari Laut Cina Selatan yang melintasi equator hingga ke Jawa. Namun saat seruak dingin lemah, Jawa mengalami penurunan curah hujan. Hal ini dikarenakan aliran udara dari Barat Australia yang hanya melewati Jawa hingga ke belahan bumi utara. Selain itu, adanya vortkes di sekitar Kalimantan juga mengakibatkan berkurangnya aliran massa udara yang mengalir ke Jawa.

\section{UCAPAN TERIMAKASIH}

Penulis mengucapkan terima kasih kepada BMKG untuk data observasi curah hujan dan juga kepada ECMWF untuk data ERA-Interim serta kepada Aphrodite Water Resources untuk data estimasi curah hujan.

\section{DAFTAR PUSTAKA}

Chang, C.P., Harr, P.A., dan Chen, H.J. (2005). Synoptic Disturbance over the Equatorial South China Sea and Western Maritime Continent during Boreal Winter. Monthly Weather Review. Vol. 133.489-503

Compo, G. P., G. N. Kiladis, and P. J. Webster. (1999). The horizontal and vertical structure of east Asian winter monsoon pressure surges. Quart. J. Roy. Meteor. Soc., 125, 29-54.

Falahah. (1992). Studi Seruak Dingin (Cold Surge) Selama Periode Musim Dingin Belahan Bumi Utara Tahun 1987-1990, Bandung: Tugas Akhir Program Studi Meteorologi ITB.

Fauzi, Ray \& Hidayat, Rahmat. (2018). Role of cold surge and MJO on rainfall enhancement over indonesia during east asian winter monsoon. IOP Conference Series: Earth and Environmental Science. 149. 012045. 10.1088/1755-1315/149/1/012045.

Heo, J.-W.; Ho, C.-H.; Park, T.-W.; Choi, W.; Jeong, J.-H.; Kim, J.(2018). Changes in Cold Surge Occurrence over East Asia in the Future: Role of Thermal Structure. Atmosphere 2018, 9, 222.

Hermawanto, A. (2011). Kajian Periode Break Saat Berlangsungnya Monsun Asia Musim Dingin Di Wilayah Indonesia, Tesis Institut Teknologi Bandung, Bandung

Jeong Yik, Diong \& Moten, Subramaniam \& Adam, Mat \& Yunus, F. (2014). Satistics of Northeast Monsoon Onset, Withdrawal and Cold Surges in Malaysia.Research Paper, MMD. 
Jones, P.D, Harpham, C, Troccoli, A, Gschwind, B, Ranchin, T, Wald, L, Goodess, C.M, Dorling, S. (2017). Using ERA-Interim Reanalysis output for creating datasets of energy- relevant climate variables. Earth Syst. Sci. Data, 9 (2017), pp. 471-495, 10.5194/essd-2016-67.

Koseki, S., Koh, T.-Y., \& Teo, C.-K. (2014). Borneo vortex and mesoscale convective rainfall. Atmospheric Physics Chemical, 14, 4539- 4562.

Lau, K.M.(1982). Equatorial Responses to Northeasterly Cold Surges as Inferred from Cloud Satellite Imagery. Mon. Weath. Rev., 110, 130613.

Lim, S. Y., C. Marzin, P. Xavier, C.-P. Chang, and B. Timbal. (2017). Impacts of boreal winter monsoon cold surges and the interaction with MJO on Southeast Asia rainfall. J. Climate, 30, 4267-4281, https://doi.org/10.1175/JCLI-D-16-0546.1.

Riehl, H. (1968). Tropical Meteorology. McGraw-Hill Book Company,392 pp.

Suppiah, Wu. (1998). Surges, cross-equatorial flows and their links with the Australian Summer Monsoon Circulation and Rainfall. Australian Meteorological Magazine 47:2

Webster, P.J. and Fasullo, J.(2003). Monsoon / Dynamical Theory. Encyclopedia of Atmospheric Science. Elsevier Science, 1370-1386

Wu, P., M. Hara, H. Fudeyasu, M. D. Yamanaka, J. Matsumoto, F. Syamsudin, R. Sulistyowati, and Y. S. Djajadihardja. (2007). The impact of transequatorial monsoon flow on the formation of repeated torrential rains over Java Island. SOLA, 3,93-96.

Xavier, P., and Coauthors. (2020). Seasonal Dependence of Cold Surges and their Interaction with the Madden-Julian Oscillation over Southeast Asia. J. Climate, 33, 2467-2482.

Yatagai, A., K. Kamiguchi, O. Arakawa, A. Hamada, N. Yasutomi, and A. Kitoh. (2012). APHRODITE: Constructing a Long-Term Daily Gridded Precipitation Dataset for Asia Based on a Dense Network of Rain Gauges. Bull. Amer. Meteor. Soc., 93, 14011415 . 